Buana Sains Vol 18 No 2: 161 - 170, 2018

\title{
STRATEGI BAURAN PEMASARAN DESA WISATA KAMPUNG EKOLOGI TEMAS DI KOTA BATU
}

\author{
Ninin Khoirunnisa dan A. Yusuf Kholil
}

Program Studi Agribisnis, Fakultas Pertanian, Universitas Tribhuwana Tunggadewi

\begin{abstract}
Marketing strategy is a plan that is done to be able to capture the market, using the $7 \mathrm{P}$ Marketing Mix strategy. This study aims to 1) analyze internal and external factors in the development of the Kampung Ekologi Batu (KEB). 2) Analyzing the development strategy that must be implemented by the Kampung Ekologi Batu (KEB) in increasing tourist visits. 3) Analyzing the development strategy is the most effective way to increase tourist visits of the Kampung Ekologi Batu (KEB). The sample used in this study is divided into 2, namely: Purposive Sampling and Accidental Sampling. Pursposive Sampling consists of: Tourism Marketing Department at the Tourism Office, Head of Community Empowerment and Development of Temas Village, General Chair of Kampung Ekologi Batu (KEB), Chair of KEB Development, and Chair of Rw 06. Accidental Sampling taken by 30 visitors. The analysis used in this study used SWOT Analysis, IFE Matrix and EFE Matrix to produce IE Matrix strategies. The results of this study indicate that the Kampung Ekologi Batu (KEB) has used $7 \mathrm{P}$ Marketing Mix (Product, price, place, promotion, People, Process and Physical Evidence) on the Internal KEB. The results of the IE Matrix obtained based on the weight and rating obtained from IFE and EFE indicate the position of the IE KEB Matrix in the Growing and Building area, which means that the business KEB is developing and has excellent potential to be able to increase tourism, and Analysis Results The most effective SWOT in the research is on the S-O strategy, namely: Improving service quality, package quality or products offered and maintaining the beauty and cleanliness of the Ecology Village and the beautiful environment.

Keywords: Analyzing; development strategy; marketing; Batu Ekologi Village; SWOT.

\section{Pendahuluan}

Indonesia merupakan negara berkembang. Saat ini Indonesia sedang menata perekonomian dalam rangka meningkatkan kesejahteraan rakyatnya. Salah satu dari program pemerintah Indonesia adalah membangun tempat tempat wisata yang sangat berpotensi menguntungkan, dan untuk menambah pemasukan devisa negara. Pariwisata dalam pembangunan ekonomi mejadi

salah satu faktor penting dalam kehidupan manusia terutama dalam kegiatan sosial dan ekonomi. Kondisi geografis indonesia yang memiliki banyak sekali pesona keindahan alam yang terhampar dari pulau sumatera hingga papua. sektor pariwisata ini menjadi peluang usaha yang menguntungkan bagi Indonesia dan merupakan sektor unggulan yang dapat berpengaruh dalam peningkatan pedapatan negara. Bukan
\end{abstract}


hanya alamnya saja, indonesia sebagai negara kepulauan yang memiliki berbagai keanekaragaman budaya yang unik, hal ini menjadi poin plus bagi indonesia dalam mengenalkan indonesia di mata dunia internasional. Untuk dapat menarik wisata kultural yang mampu mendorong keinginan wisatawan mancanegara. Potensi pariwisata ini di harapkan mampu membangun kemajuan perekonomian indonesia dalam mensejahterakan masyarakatnya. Dalam pengembangan desa wisata, perlu mengacu pada Undang- Undang Kepariwisataan No. 10 Tahun 2009 yang isi dan tujuannya adalah sumber daya dan modal tersebut perlu dimanfaatkan secara optimal melalui penyelenggaraan kepariwisataan yang ditujukan untuk meningkatkan pendapatan nasional, memperluas dan memeratakan kesempatan berusaha dan lapangan kerja, mendorong pembangunan daerah memperkenalkan dan mendayagunakan daya tarik wisata dan destinasi di Indonesia, serta memupuk rasa cinta tanah air dan mempererat persahabatan antar bangsa. Makna yang terkandung dalam tujuan pada UU tersebut ialah di harapkan dari sektor pariwisata dapat membawa kesejahteraan dan rasa cinta kepada semua lapisan masyarakat.

Kampung Wisata Ekologi Batu yang ramah lingkungan dengan menawarkan wisata edukasi daur ulang sampah yang dapat di manfaatkan ulang sebagai sesuatu yang bernilai jual. Kampung Wisata Ekologi sendiri telah di kunjungi 2 ribu wisatawan domestik pada tahun 2017, pada tahun 2018 Kelurahan Temas menargetkan kunjungan wisatawan 4 ribu wisatawan, untuk menarik minat wisatawan untuk berkunjung Kelurahan Temas Kecamatan Batu akan terus menambah wahana menarik. Melihat latar belakang Kampung Ekologi Batu yang masih baru
1 tahun berjalan perlu adanya strategi pemasaran yang tepat dalam pengembangan wisata di Kelurahan Temas terutama dalam strategi pengembangan pemasaran pariwisata mengenalkan Kampung Wisata ke masyarakat luas. Pengenalan pariwisata di Kelurahan ini, yang di lakukan, di nilai masih amat rendah sehingga perlu adanya strategi pengembangan pemasaran yang tepat mengenai informasi pariwisatanya, sedangkan jumlah kunjungan wisatawan, baik Lokal maupun Domestik mengalami kenaikan setiap tahunnya. Peranan pemasaran pariwisata dapat pula meningkatkan pengetahuan yang luas bagi kepentingan pariwisata, terutama pangsa pasar utama terdapat upaya pelestarian produk - produk wisata secara berkelanjutan. Strategi pemasaran menyediakan kerangka kordinasi, sehingga para pemangku kepentingan pariwisata yakni Dinas Pariwisata yang bertanggung jawab terhadap objek-objek wisata akan memiliki arah yang sama dalam upaya pengembangan mengelola destinasi dan mempromosikan pariwisata di daerahnya (KEB, 2018).

\section{Metode Penelitian}

Penelitian ini dilaksanakan pada Dusun Besul RW VI, Kelurahan Temas, Kota Batu. Pemilihan lokasi penelitian ini di lakukan secara (Purposive) dengan pertimbangan bahwa Kelurahan Temas RW VI, sebagai kampung wisata ramah lingkungan yang dapat di jadikan contoh dan edukasi bagi kelurahan - kelurahan atau desa desa lain untuk menjaga lingkungan kelurahan dan desanya.Pengumpulan data penelitian ini akan mulai dilaksanakan pada bulan April - Juni 2018.

Data yang di gunakan dalam penelitian ini adalah data primer dan 
N. Khoirunnisa dan Y. Kholili/ Buana Sains Vol 18 No 2 : 161-170

data sekunder. Data primer yang di lakukan yaitu observasi, wawancara, kuesioner dan dokumentasi. Data sekunder yang di peroleh pada pada penelitian ialah dari Kantor Kelurahan Temas dan BPS.

Pemilihan responden penelitian ini di bagi menjadi 2 yaitu responden berdasarkan Purposive Sampling dan responden berdasarkan Accidental Sampling. Responden Purposive Sampling (Internal) dalam penelitian ini adalah Pengurus KEB dan Intansi Dinas Pariwisata yang terkaitdengan Kampung Ekologi sendiri, yang sampelnya di ambil secara sengaja (Purposive Sampling) dengan cara memilih orang - orang tertentu yang di anggap mampu memberikan keterangan mengenai Strategi Bauran Pemasaran Pariwisata, seperti : Kabid Pemasaran Wisata pada Dinas Pariwisata, Kasi Pemberdayaan Masyarakat dan Pembangunan Kelurahan Temas, Ketua Umum Kampung Ekologi Batu (KEB), Ketua bidang Pengembangan KEB, dan Ketua Rw 06. Responden Accidental Sampling (Eksternal) yang akan di butuhkan dalam penelitian ini merupakan responden yang berasal dari 30 orang pengunjung wisatawan lokal maupun domestik. Berdasarkan penyebaran kuesioner kepada 30 orang maka akan di temukan faktor - faktor yang menjadi kekuatan, kelemahan, peluang dan ancaman pada Kampung Ekologi Batu.

Analisis data di lakukan secara kualitatif dan kuantitatif dan melalui tiga tahapan. Pertama disebut pengumpulan data (the input stage), kedua tahap pencocokan (the matching stage), dan terakhir tahap keputusan (the decision stage). Dalam mengidentifikasi hasil faktor Internal di gunakan tahap pengumpulan data yaitu dengan strategi matriks IFE Internal Factor Evaluation)dan EFE (External Factor Evaluation) sedangkan untuk menganalisis tahap permasalahan selanjutnya digunakan tahapan dua yaitu dengan menggunakan strategi Matriks IE (Internal and External) dan matriks SWOT (Strength, weakness, Opportunities and Treaths), dan kemudian merumuskan alternatif strategi pemasaran yang efektif.

\section{Hasil dan Pembahasan}

\section{Identifikasi Faktor Internal dan Eksternal}

Berdasarkan analisis terhadap lingkungan internal yang mengacu pada aktivitas usaha KEB yang terdiri dari sistem Manajemen, Pemasaran, Produksi/Operasi, dan Keuangan, maka diperoleh sejumlah faktor kekuatan dan kelemahan yang terkait pada aktivitas tersebut. Analisis terhadap lingkungan eksternal yang mengacu pada aktivitas usaha KEB maka dapat diidentifikasikan beberapa faktor yang dapat menjadi dimiliki oleh perusahaan yang terdiri dari lingkungan makro dan lingkungan mikro. Analisis terhadap factor internal dan eksternal terlihat pada tabel 1 dan 2 . 
Tabel 1. Identifikasi Faktor Internal KEB

\begin{tabular}{cl}
\hline No & \multicolumn{1}{c}{ Kaktor - Faktor Internal } \\
\hline \multicolumn{1}{c}{ Kekuatan (S) } \\
\hline 2 & Adanya edukasi daur ulang sampah dan pelatihan tanaman organik sebagai nilai jual \\
\hline 3 & $\begin{array}{l}\text { Harga paket yang berlaku di Kampung Ekologi Batu (KEB)sesuai dengan kualitas } \\
\text { produk, pelayanan dan fasilitas wisata yang di tawarkan. }\end{array}$ \\
\hline 4 & Bahasa penyampaian dan inovasi tempat wisata sudah menarik dalam hal promosi \\
\hline 5 & $\begin{array}{l}\text { Ketertarikan pengunjung melalui promosi dengan menggunakan media digital internet } \\
\text { dan media sosial sudah efektif dalam penyebaran Wisata Ekologi. }\end{array}$ \\
\hline 6 & Keberadaan lokasi Kampung Ekologi Batu strategis dan mudah di temukan. \\
\hline 7 & Keamanan di Kampung Ekologi sudah cukup baik. \\
\hline 8 & Suasana lokasi di Kampung Ekologi nyaman untuk berwisata. \\
\hline 9 & Kebersihan Kampung Ekologi Batu sudah terjaga dengan baik. \\
\hline 10 & Petugas di KEB sudah bersikap ramah, dan sopan kepada pengunjung. \\
\hline 11 & Kesigapan karyawan yang bertugas Kampung Ekologi Batu sudah baik. \\
\hline 12 & Petugas di KEB respons terhadap keadaan yang dialami pengunjung. \\
\hline 13 & Petugas di KEB aktif berkomunikasi dan memberikan informasi kepada pengunjung. \\
\hline 14 & Petugas di KEB menggunakan bahasa yang baik dan benar serta mudah dimengerti. \\
\hline 15 & $\begin{array}{l}\text { Proses manajemen keuangan kampung wisata ekologi berjalan dengan baik dan optimal } \\
\text { untuk pengembangan wisata secara berkesinambungan. }\end{array}$ \\
\hline 16 & Tata letak bangunan dan design lokasi Kampung Ekologi Batu sudah baik. \\
\hline &
\end{tabular}

1 Perlu adanya tambahan wahana atau lokasi wisata baru yang menarik perhatian pengunjung dengan pertimbangan tingkat persaingan usaha yang semakin pesat.

2 Spot foto Kampung Wisata Ekologi belum menarik terhadap perhatian pengunjung.

3 Upaya promosi Kampung Ekologi Batu belum berjalan secara optimal.

4 Website Kampung Ekologi Batu belum berjalan secara berkesinambungan memberikan informasi wisata KEB.

$5 \quad$ Strategi promosi melalui event - event dan public relations yang di adakan belum terlaksana secara kontinuitas dalam menarik minat pengunjung wisatawan.

6 Area tempat parkir belum berada pada koridor yang seharusnya luas dan aman.

7 Belum adanya pendamping wisatawan khusus Individu

8 Struktur organisasi Kampung Ekologi Batu belum berjalan sesuai dengan tugas dan fungsinya masing - masing.

9 Proses pelayanan karyawan Kampung Ekologi Batu belum maksimal.

10 Kemudahan akses pemesanan, di Kampung Ekologi Batu belum maksimal.

11 Proses pelayanan bahasa asing kepada wisatawan mancanegara yang berkunjung masih belum optimal.

12 Belum adanya kerjasama dengan pihak luar

13 Kelengkapan dan kelayakan fasilitas penunjang (toilet, mushola, tempat parkir) di Kampung Ekologi Batu belum memadai. 
N. Khoirunnisa dan Y. Kholili/ Buana Sains Vol 18 No $2: 161-170$

Tabel 2. Identifikasi Faktor Eksternal KEB.

\begin{tabular}{ll}
\hline No & \multicolumn{1}{c}{ Faktor - Faktor Eksternal } \\
\hline 1 & $\begin{array}{l}\text { Daya tarik pengunjung torhadap paket wisata yang ditawarkan Kampung } \\
\text { Ekologi Batu sudah sangat menarik. }\end{array}$ \\
\hline 2 & $\begin{array}{l}\text { Konsep Kampung Ekologi Batu yang ditawarkan sudah cukup menarik } \\
\text { perhatian masyarakat untuk berkunjung. }\end{array}$ \\
\hline 3 & $\begin{array}{l}\text { Kampung Ekologi Batu sebagai kampung Ekologi yang mengajarkan edukasi } \\
\text { yang ramah lingkungan satu - satunya yang berada di Kota Batu. }\end{array}$ \\
\hline 4 & Proses adanya dukungan dari Dinas Kebudayaan dan Pariwisata Kota Batu. \\
\hline 5 & Proses adanya dukungan dari Kelurahan Temas. \\
\hline 6 & $\begin{array}{l}\text { Kampung Ekologi Batu Memiliki reputasi yang baik terhadap implementasi } \\
\text { edukasi ramah lingkungan. }\end{array}$ \\
\hline \multicolumn{4}{c}{ Ancaman (T) } \\
\hline 1 & $\begin{array}{l}\text { Keberadaan pesaing sejenis yang sama dalam prospek wisata kampung dengan } \\
\text { wisata yang berbeda. }\end{array}$ \\
\hline 2 & $\begin{array}{l}\text { Proses menuju Kampung Ekologi Batu senantiasa macet dengan arus lalu lintas } \\
\text { perkotaan. }\end{array}$ \\
\hline
\end{tabular}

\section{Analisis Matriks IE}

Matriks IE merupakan perpaduan dari skor terbobot matriks IFE dan skor terbobot matriks EFE yang dipetakan sehingga diketahui posisi perusahaan berdasarkan hasil analisis faktor internal menggunakan matriks
IFE diperoleh bobot skor sebesar 3,25 dan hasil analisis faktor eksternal menggunakan matriks EFE diperoleh bobot skor sebesar 3,63. Hasil pemetaan pada matriks IE dapat dilihat pada gambar 1 dibawah ini.

Total Skor IFE

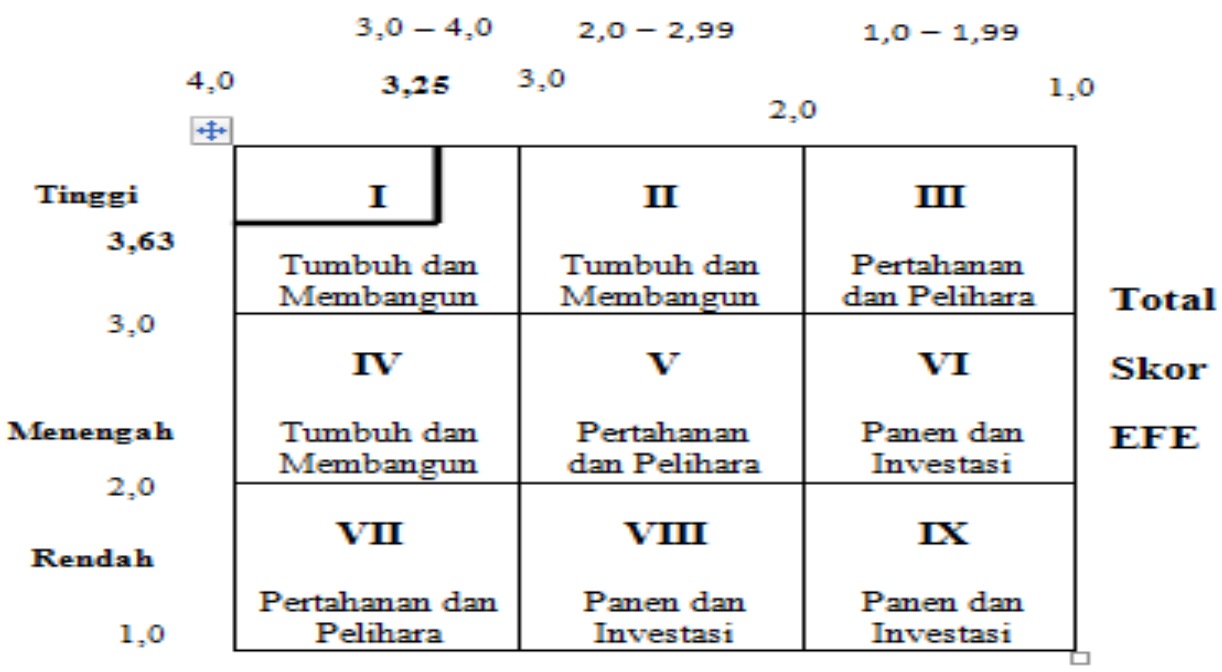

Gambar 1. Hasil matriks IE kampung Ekologi Batu 


\section{Analisis Matriks SWOT}

Berdasarkan Kekuatan,

Kelemahan, Peluang dan Ancaman yang diperoleh melalui Internal dan Eksternal, dapat diformulasikan alternatif strategi yang diambil. Formulasi strategi ini dilakukan dengan menggunakan Analisis SWOT :

\section{Strategi S-O (Strength-Opportunity)}

Strategi S-O merupakan strategi yang menggunakan kekuatan internal perusahaan untuk memanfaatkan peluang eksternal. Alternatif strategi yang dilakukan pada strategi $\mathrm{S}$ - O yaitu:

a. Meningkatkan mutu pelayanan, mutu paket atau produk yang di tawarkan dan menjaga keindahan dan kebersihan Kampung Ekologi Batu sehingga terciptanya lingkungan yang asri.

b. Menambah inovasi tempat yang baru untuk dapat menarik minat kunjungan wisatawan.perlu adanya tempat wisata yang baru di ruang lingkup kampung ekologi batu. Dengan adanya tambahan wahana baru dapat menarik minat kunjungan wisatawan ke Kampung Ekologi Batu, membuat tempat outbond atau menambah tempat spot foto.

c. Menjalin dan membangun kemitraan dengan beberapa Stakholder untuk menjadikan KEB menjadi lebih baik lagi. Kampung Ekologi Batu sebagai kampung yang masih baru yang muncul kedunia wisata dengan konsep Kampung Wisata Ekologi yang mengarah pada konsep pembaharuan, perlu adanya kerja sama yang saling menguntungkan dengan beberapa stakholder, sehingga proses pembangunan apa saja yang di inginkan pengelola/pengurus dapat terealisasi.

d. Mengoptimalkan kegiatan promosi, memiliki Website KEB demi menyampaikan Informasi berkaitan dengan kegiatan KEB kemasyarakat luas. Penting strategi ini dalam proses pengembangan wisata, dengan ada Website yang sifatnya pribadi dan terkhususkan kepada kegiatan yang di lakukan KEB maka dapat terpantau oleh masyarakat luas.

e. Menyalurkan dan mengenalkan hasil kreativitas kerajinan tangan daur ulang sampah dan hasil pertanian hortikultura organik yang di produksi oleh Kampung Ekologi Batu kemasyarakat luas. Strategi ini merupakan cara yang selanjutnya yang harus di gunakan KEB dalam bentuk mengenalkan KEB ke masyarakat luas. Dengan begitu masyarakat akan langsung mengenal Kampung Ekologi Batu melalui kreatifitas kerajinan yang di buat oleh pengrajin - pengrajin kreatifitas KEB.

f. Mengoptimalkan sistem manajemen organisasi yang berkaitan koordinasi antar pengurus dan warga setempat sehingga terciptanya rasa memiliki terhadap pengembangan Kampung Ekologi Batu. Perlu adanya keeratan dalam proses koordinasi pengurus dengan pengurus dan pengurus dengan warga KEB, dengan begitu koordinasi dan proses komunikasi akan selalu terjaga dan proses pengembangan KEB akan cepat tumbuh dan berkembang seperti yang di 
N. Khoirunnisa dan Y. Kholili/ Buana Sains Vol 18 No 2 : 161-170

$\begin{array}{lcr}\text { harapkan } & \text { oleh } & \text { seluruh } \\ \text { stakeholder } & \text { Kampung } & \text { Ekologi } \\ \text { Batu. } & & \end{array}$

\section{StrategiW-O (Weakness-Opportunity)}

Strategi W-O adalah strategi yang menggunakan peluang yang ada untuk mengatasi kelemahan-kelemahan yang dimiliki perusahaan. Ada beberapa alternatif strategi yang dapat dilakukan pada strategi W-O yaitu:

a. Meningkatkan kreativitas yang inovatif dan kreatif untuk dapat menarik minat wisatawan berkunjung. Strategi ini dilakukan untuk dapat menciptakan suatu kreatifitas yang baru sehingga tidak selalu dengan produk sama.

b. Mengoperasikan media sosial dan media digitalwebsite untuk sarana penyampaian informasi dan promosi secara inovatif, aktif dan efisien. Melakukan pemasaran dan promosi secara inovatif, efektif dan efisien. Strategi ini dapat berupa bekerjasama dengan media cetak maupun media elektronik saat mempromosikan KEB. Selain itu, ikut berpartisipasi pada event atau pameran wisata yang akan menjadikan KEB menjadi salah satu pilihan destinasi wisata bagi pengunjung. Pemberian diskon bagi pengunjung dalam bentuk rombongan dapat dilakukan untuk menarik perhatian pengunjung. Dengan ini diharapkan terjadi peningkatan jumlah pengunjung tiap tahunnya.

c. Memperbaiki tatanan organisasi yang masih belum berjalan secara optimal. Perlu ada peningkatan dalam proses pengembangan wisata dengan memperkuat struktur organisasi dari dalam seperti penjadwalan pertemuan antar pengurus membahas program - program yang akan di laksanakan dan pula evaluasi evaluasi dini yang sifatnya cepat tanggap terhadap persoalan yang di hadapi.

d. Meningkatkan kualitas SDM. Meningkatkan kreativitas petugas atau pemandu yang bertugas melalui pelatihan SDM agar terciptanya produk yang inovatif dan kreatif. Pelatihan SDM yang dimaksudkan agar dapat memunculkan ide - ide kreatif pengurus. Sehingga para pengurus atau pemandu yang bertugas dapat memunculkan ide - ide yang kreatif dan inovatif ketika dihadapkan dengan masalah di lapangan. Selain itu pula, pada saat memandu para wisatawan para pemandu dapat mengeksplorasi pengetahuannya tentang paket wisata yang sedang dilakukan sehingga pengunjung tertarik dan puas.

e. Meningkatkan sarana dan prasarana yang baik untuk kenyamanan para pengunjung (wisatawan). Penambahan fasilitas bertujuan untuk kelancaran usaha seperti yang keinginan Kampung Ekologi sendiri seperti mempunyai: Sekretariat, towa, mic, komputer, print yang sifatnya pribadi demi kelancaran operasional dan yang lainnya perlu adanya pembangunan halte - halte atau aula peristirahatan sementara yang di gunakan pengunjung untuk menikmati wisata yang di tawarkan Kampung Ekologi Batu. 


\section{Strategi S-T (Strength-Threat)}

Strategi ini bertujuan untuk menghindari atau mengurangi dampak dari ancamanancaman eksternal dengan menggunakan kekuatan-kekuatan internal yang ada. Ada beberapa alternatif yang dapat dilakukan pada strategi S-T yaitu:

a. Mempertahankan serta dapat meningkatkan mutu produk, pelayanan dan penambahan fasilitas KEB, terhadap banyaknya pesaing yang bermunculan. Strategi ini penting untuk di lakukan yang mana konsumen/pengunjung sudah lebih mementingkan wisata yang lebih memprioritaskan produk, pelayanan dan fasilitas yang telah di tujuan wisata yang akan di kunjungi, sehingga Pengurus KEB sudah seharusnya memperbaiki seluruh tatanan operasional KEB demi kenyamanan pengunjung wisatawan.

b. Mengadakan event event/perlombaan pembuatan kerajinan daur ulang sampah menjadi barang jadi yang bernilai. Mengadakan acara merupakan strategi penting yang harus di terapkan, dengan adanya acara/event - event yang di laksanakan oleh KEB, semakin banyak pemberitaan yang akan di sampaikan dan semakin banyak pula informasi yang di terima masyarakat terhadap Kampung Ekologi Batu.

c. Menyediakan petugas pengatur arus lalu lintas yang berjaga di depan pintu KEB sehingga tidak terjadi kemacetan. Pentingnya petugas pengatur arus lalu lintas di depan gerbang KEB ini penting untuk di lakukan karena Kota Batu di kenal Kota Wisata, yang banyak memiliki destinasi wisata, sehingga arus lalu lintas akan terhambat jika tidak adanya petugas yang mengatur lalu lintas.

\section{Strategi W-T (Weakness-Thread)}

Strategi W-T adalah strategi dimana perusahaan dapat meminimalkan kelemahan dan menghindari ancaman. Salah satu alternatif strategi yang dapat dilakukan pada strategi W-T yaitu:

a. Menguatkan citra baik Kampung Ekologi Batu yang telah ada agar dapat meminimalisasi persaingan. Dengan adanya kepercayaan dan pengetahuan masyarakat terhadap adanya edukasi yang memberikan metode cara daur ulang sampah sebagai barang jadi yang di kreativitaskan sedemikian rupa oleh pengerajin dan proses pembelajaran tata cara merawat tanaman organik satu - satunya berada di Kota Batu, ini menjadi kesempatan utama dalam meningkatkan pandangan positif dari masyarakat dan pengunjung terhadap Kampung Ekologi Batu.

b. Meningkatkan pelayanan yang baik kepada pengunjung Kampung Ekologi Batu (KEB) untuk menghadapi persaingan. Strategi ini penting untuk di lakukan terlebih banyaknya pesaing yang menawarkan banyak jenis wisata dengan pelayanan yang memuaskan bagi para pengunjung. 


\section{Kesimpulan}

Berdasarkan hasil penelitian yang di laksanakan di Kampung Ekologi Batu, maka penulis dapat menyimpulkan halhal sebagai berikut :

1. Faktor Internal Kampung Ekologi Batu ( KEB ), menggunakan Strategi Bauran Pemasaran (Marketing Mix) antara lain, strategi product : Adanya edukasi daur ulang sampah dan pelatihan tanaman organik sebagai nilai jual utama dalam tawaran wisata sudah cukup baik. Strategi Price : Harga paket yang berlaku di Kampung Ekologi Batu sesuai dengan kualitas produk, pelayanan dan fasilitas wisata yang di tawarkan sudah baik. Strategi Place :Keberadaan lokasi KEB strategi dan mudah di temui sangat baik. Strategi Promotion : Bahasa penyampaian dan inovasi tempat adalah baik, dalam promosi yang di publikasikan. Strategi People : Orang - orang yang bertugas di Kampung Ekologi Batu sudah bersikap cukup baik, ramah, dan sopan kepada pengunjung.Strategi Process : Proses manajemen keuangan kampung wisata ekologi berjalan dengan baik dan optimal untuk pengembangan wisata secara berkesinambungan. Strategi Physical Evidence : Tata letak bangunan dan design lokasi Kampung Ekologi Batu sudah baik. Faktor Eksternal KEB : Strategi Product : Daya tarik pengunjung terhadap paket wisata yang ditawarkan Kampung Ekologi Batu sudah sangat baik/menarik. Stategi Place : Kampung Ekologi Batu sebagai kampung Ekologi yang mengajarkan edukasi yang ramah lingkungan satu - satunya yang berada di Kota Batu sangat baik. Strategi Process : Proses adanya dukungandari Dinas Kebudayaan dan Pariwisata Kota Batu dan di tambah lagi adanya dukungan penuh dari pihak Kantor Kelurahan Temas. Strategi Physical Evidence : Kampung Ekologi Batu Memiliki reputasi yang baik terhadap implementasi edukasi ramah lingkungan.

2. Berdasarkan Strategi IE yang harus di terapkan KEB, dalam meningkatkan kunjungan wisatawan pada posisi ini adalah Penetrasi Pasar : Meningkatkan strategi promosi melalui media digital, media sosial dan media televisi.Mendistribusikan hasil hasil kerajinan daur ulang sampah ke toko - toko dan pusat oleh oleh yang ada di sekitaran Kota Batu dan Kota Malang.Membuat buku petunjuk, rambu - rambu penunjuk arah lokasi seperti plang nama dan peta lokasi KEB.Pengembangan Produk : Meningkatkan kualitas mutu produk, dan Memperbaharui produk/jasa yang di tawarkan.Pengembangan Pasar : Mengiformasikan KEB ke wilayah baru dengan memasang Banner, Spanduk dll. Meningkatkan paket wisata yang sesuai harga dengan keinginan pengunjung.Menambah variasi paket/produk wisata yang berbeda.

3. Berdasarkan Analisis SWOT didapatkan alternatif Strategi Pemasaran Kampung Ekologi Batu yaitu: Strategi S - O : (a) Meningkatkan mutu pelayanan, 
mutu paket atau produk yang di tawarkan dan menjaga keindahan dan kebersihan Kampung Ekologi Batu sehingga terciptanya lingkungan yang asri. (b) Menambah inovasi tempat yang baru untuk dapat menarik minat kunjungan wisatawan. (c) Menjalin dan membangun kemitraan dengan beberapa Stakholder untuk menjadikan KEB menjadi lebih baik lagi. (d) Mengoptimalkan kegiatan promosi Kemasyarakat luas, memiliki Website KEB demi menyampaikan Informasi berkaitan dengan kegiatan KEB. (e) Menyalurkan dan mengenalkan hasil kreativitas kerajinan tangan daur ulang sampah dan hasil pertanian hortikultura organik yang di produksi oleh Kampung Ekologi Batu kemasyarakat luas. (f) Mengoptimalkan sistem manajemen organisasi yang berkaitan koordinasi antar pengurus dan warga setempat sehingga terciptanya rasa memiliki terhadap pengembangan Kampung Ekologi Batu.

\section{Daftar Pustaka}

David, F.R. 2006. Manajemen Strategi Edisi Kesepuluh. PT INDEKS Kelompok Gramedia. Jakarta.

Kotler, P. 2008. Manajemen Pemasaran Edisi 12 Jilid 2. Jakarta : Indeks

Kotler, P. \& Keller. 2012. Manajemen Pemasaran. Edisi 12. Jakarta : Erlangga

Kotler, P. 2005. Dasar - dasar Pemasaran, Edisi II, PT Indeks
Kelompok, Jakarta : Kelompok Gramedia

Nurulwaasi, M. Marsya. 2017. Analisis strategi promosi dalam pengembangan pariwisata. Jurusan Ilmu Administrasi Bisnis. Fakultas Ilmu Sosial dan Ilmu Politik. UniversitasLampung.

Saragih, A. Wisdawati. 2011. Analisis Strategi Pemasaran Kampoeng Wisata Cinangneng Kabupaten Bogor Jawa Barat. Departemen Agribisnis. Fakultas Ekonomi dan Manajemen. Institut Pertanian Bogor.

Tjiptono, Fandy. 2008, Strategi Pemasaran Edisi $\mathrm{Ke} \mathrm{3,}$ Yogyakarta : Andi Office.

Tjiptono, Fandy. 2014, Pemasaran Jasa, Andi. Yogyakarta.

Tjiptono, F. Strategi Pemasaran, Ed Ke 2 ( Yogyakarta: ANDI, 1997. Pidato pengukuhan Prof. Sumeru Ashari : Buah Tropis Indonesia Mampu Bersaing.

Yunita, 2015. Strategi Pengembangan Pariwisata Di Desa Sawarna Kecamatan Bayah Kabupaten Landak.Skripsi. Program Studi Ilmu administrasi negara. Fakultas Ilmu Sosial dan Ilmu Politik. Universitas Sultan Ageng 